\title{
USE OF CONCENTRATED SOLUTION OF LECITHIN IN KAHN ANTIGEN*†
}

\author{
BY \\ ELIZABETH B. MCDERMOTT, FRANK T. NAKAMURA, MARY R. DOCKRILL, \\ AND REUBEN L. KAHN
}

Serology Laboratory, University Hospital, and Department of Dermatology and Syphilology, University of Michigan Medical School, Ann Arbor, Michigan

In the standardization of Kahn antigen, a lipid extract is occasionally encountered which, on being mixed with salt solution, results in an antigen suspension containing non-dispersible lipid aggregates. Such a suspension obviously cannot be used in a flocculation test for syphilis, because, when it is mixed with non-syphilitic serum, instead of the result being total freedom from particles in the serum-suspension mixture, the presence of these non-dispersible aggregates is bound to be confused with floccules of a syphilitic reaction.

Indications are that the non-dispersibility of these aggregates in the antigen-salt solution suspension is due to a disproportionate amount of lecithin to cardiolipin or a cardiolipin-like substance contained in the lipid extract. The term "cardiolipin", being a familiar one, will be used in this article instead of "cardiolipin-like substance". Briefly, it is assumed that Kahn antigen contains lecithin, cardiolipin, cholesterol, and additional lipids of undetermined nature. When the antigen is mixed with salt solution, the cardiolipin in the antigen tends to render the antigen suspension aggregates nondispersible, while the lecithin in the antigen tends to disperse them. When cardiolipin and lecithin are in proper equilibrium, a desirable antigen results, and the aggregates are in an optimum state for dispersion in additional salt solution or in serum. When one or the other lipids is in excess, the antigen requires appropriate correction.

That cardiolipin and lecithin play a major role in Kahn antigen can be judged from the fact that this antigen and cardiolipin-lecithin-cholesterol antigen behave with close similarity in the Kahn technique (Kahn, 1950). The formula for cardiolipin-lecithincholesterol antigen, as used in the Kahn technique in this laboratory side by side with Kahn antigen,

\footnotetext{
* Received for publication June $3,1957$.
+ This study was aided by a grant from the Difco Laboratories, Inc., Detroit, Mich., U.S.A.
}

consists of approximately 1 per cent. lecithin, $0 \cdot 1$ per cent. cardiolipin, and 0.025 per cent. cholesterol in absolute alcohol. In the preparation of the antigen suspensions with Kahn and with cardiolipinlecithin-cholesterol antigens, the same technique is employed for mixing the antigen with the salt solution. The resulting antigen suspensions have essentially the same physical appearance and show the same behaviour with salt solution and serum. The titre of cardiolipin-lecithin-cholesterol antigen is obtained by following the same technique as for the titre of Kahn antigen. When the two antigens are employed side by side in the three serum: antigen suspension ratios in the Kahn test, the resulting serologic pattern is also essentially the same. For example, a serum showing a reading of, say, -24 with Kahn antigen, is likely to show the same reading with the cardiolipin-lecithin-cholesterol antigen.

Quantitative chemical determinations of cardiolipin and lecithin in Kahn antigen, in relation to the other lipids present, are under study in this laboratory. Thus far, Kahn antigen has yielded lecithin and a cardiolipin-like substance qualitatively, by purification of barium and cadmium precipitates, according to Pangborn's methods (Pangborn, 1945, 1951).

The role of the additional lipids in Kahn antigen, apart from the cardiolipin, lecithin, and cholesterol, is believed to be somewhat similar to that of "protective" colloids to the cardiolipin and lecithin. This view is suggested by the fact that the Kahn test with cardiolipin-lecithin-cholesterol antigen is far more readily affected by slight variations in technique than the same test with Kahn antigen. The test with Kahn antigen seems technically hardy compared with the test with cardiolipin-lecithincholesterol antigen.

It is possible also that the additional lipids in Kahn antigen play an important role in the universal 
serologic reaction (Kahn, 1951). Cardiolipinlecithin-cholesterol antigen, when used according to the formula employed in the Kahn technique, is not as applicable to the technique of the universal reaction as is Kahn antigen. It may be, however, that a modified formula would make cardiolipinlecithin-cholesterol antigen fully applicable to the universal reaction.

In this article we are concerned particularly with attempts to standardize such Kahn antigens as are occasionally encountered which, when mixed with salt solution, result in antigen suspensions containing non-dispersible aggregates, and which cannot therefore be used with serum. First, the several steps in the standardization of Kahn antigen will be briefly reviewed. Then, the results of an experiment will be presented showing that the addition of cardiolipin to Kahn antigen changes the antigen-salt solution suspension of dispersible aggregates to a suspension of non-dispersible aggregates; and the subsequent addition of lecithin to the antigen leads to an antigen suspension in which the aggregates have again become dispersible. Finally, data will be presented of the correction of antigens, which give suspensions with salt solution of non-dispersible aggregates, to the requirements of standard Kahn antigen by the addition of small amounts of a concentrated lecithin solution.

\section{Standardization of Kahn Antigen}

The conversion of a newly prepared lipid extract into standard Kahn antigen requires three basic steps:

(1) The determination of the antigen titre with 0.9 per cent. $\mathrm{NaCl}$ solution is accomplished by means of a titration in which each of several amounts of salt solution is appropriately mixed with $1 \mathrm{ml}$. antigen. The titre indicates the correct quantity of salt solution to be mixed with the antigen, under standard conditions, for the production of an antigen suspension fit for trial use with serum. The correct type of suspension contains lipid aggregates of such physical nature that they disperse spontaneously when added to serum or to salt solution.

(2) When the antigen suspension at the antigen titre is mixed with syphilitic serum, the dispersion of the lipid suspension aggregates is followed by the rapid formation of new lipid-globulin floccules. These floccules should have the same qualitative and quantitative characteristics as those obtained with standard Kahn antigen.
(3) When the antigen suspension is mixed with non-syphilitic serum, no lipid-globulin floccules are formed. In addition, the resulting mixture must have a degree of opalescence which conforms to standard requirements. The opalescence must be free from turbidity on the one hand and from over-clarity on the other.

A newly-prepared lipid extract may not conform to the first standardization requirement by not giving an antigen titre. Thus, no matter in what proportion this extract is mixed with salt solution throughout the titre range, the resulting lipid aggregates are not dispersible in serum. That extract is therefore not fit for trial use with serum, since all sera, whether syphilitic or non-syphilitic, will show the presence of these aggregates. Alternatively, if the extract does give a titre with salt solution, trial tests with serum might show that both the sensitivity with syphilitic serum and the degree of opalescence with nonsyphilitic serum are out of range compared with standard Kahn antigen.

The use of 5 per cent. solutions of commercial lecithin in the correction of over-sensitive antigens was previously reported from this laboratory (Wheeler, Brandon, and Kahn, 1947). Because of the weak solution of this type of lecithin, relatively large amounts had to be added to an antigen for correction and this fact greatly limited its use. Experience with the use of solutions of purified lecithin of about 50 per cent. concentration in the standardization of Kahn antigen showed that lipid extracts, which were outside the standardization range because of nondispersible aggregates in the antigen suspension and which ordinarily would have had to be discarded, became convertible into standard antigen. Many of these extracts gave no titre and therefore could not be tested with serum. Others that did give a titre showed a degree of sensitivity with syphilitic serum, or of opalescence with non-syphilitic serum, not in conformity with standard antigen. In the subsequent pages, several instances will be presented of such extracts which were corrected to standard requirements.

\section{Effect of Adding Cardiolipin* and Lecithin* to Kahn Antigen}

Preliminary experiments indicated that cardiolipin added to Kahn antigen tends toward nondispersion of the lipid aggregates in the antigen suspension, while lecithin added to the antigen tends toward their dispersion. These opposing tendencies

\footnotetext{
* Cardiolipin and concentrated lecithin solutions employed in this experiment were kindly furnished by the Difco Laboratories Inc., Detroit.
} 
of cardiolipin and lecithin are illustrated in the following experiment.

To $100 \mathrm{ml}$. standard Kahn antigen (Lot 214 in current use) were added $50 \mathrm{ml} .0 .6$ per cent. cholesterolized alcohol, the percentage of cholesterol being the same as in the Kahn antigen. The dilution of the antigen was desired in order to reduce the amounts of cardiolipin and lecithin to be used in the experiment.

The diluted antigen, which obviously no longer conformed to the requirements of standard Kahn antigen, was then divided into 7 fractions of $10 \mathrm{ml}$. each.

Fraction 1 was titrated in the usual manner with salt solution. The titration range was $1 \mathrm{ml}$. antigen $+1 \cdot 1 \mathrm{ml}$. salt solution; $1 \mathrm{ml}$. antigen $+1.2 \mathrm{ml}$. salt solution; $1+1.3 ; 1+1.4$; and $1 \mathrm{ml}$. antigen $+1.5 \mathrm{ml}$. salt solution. All five titration mixtures (in Fraction 1) contained lipid aggregates which were readily dispersed on the addition of salt solution, leading to very nearly water-clear solutions, because of the high dilution of the antigen with the cholesterolized alcohol.

To Fraction 2 was added 0.1 per cent. $(10 \mathrm{mg}$.) cardiolipin and the modified antigen was titrated with salt solution. The antigen plus salt solution mixtures of $1+1 \cdot 1$ and $1+1 \cdot 2$ now showed aggregates which were only partially dispersed on adding salt solution. The remaining antigen plus salt solution mixtures showed aggregates which were completely dispersed and which were apparently not affected by the small amount of cardiolipin added to the antigen.

When 0.5 per cent. (50 mg.) cardiolipin was added to Fraction 3, four of the titration mixtures $(1+1 \cdot 1$, $1+1 \cdot 2,1+1 \cdot 3$, and $1+1 \cdot 4)$ showed aggregates which were non-dispersible, and the last mixture $(1+1 \cdot 5)$ showed aggregates partially dispersible. When, however, not only 0.5 per cent. cardiolipin but also 0.5 per cent. of a lecithin solution of high ( 28 per cent.) concentration, were added to Fraction 4, the titration picture began to show a change from non-dispersibility toward dispersibility of the aggregates.
As is evident from the results given by Fractions 5 and 6 in Table 1,2 per cent. of the concentrated lecithin solution was required to overcome the non-dispersible tendency of the lipid aggregates brought about by the 0.5 per cent. cardiolipin. Antigen Fraction 7 was used as a control.

In the present article, that property of lecithin which changes non-dispersible to dispersible suspensions is stressed because it offers a means for the standardization of antigens which, on preparation, show non-dispersible aggregates in the suspensions and, as indicated, would be unfit for use.

\section{Use of Concentrated Lecithin in Standardization of Kahn Antigen}

The lecithin solutions were prepared from egg yolk according to Pangborn's procedure (Pangborn, 1951), with the exception that, after the last step in the purification, the ether-acetone solution of the lecithin was dried in vacuo. A concentrated solution was then prepared by the addition of $2 \mathrm{ml}$. absolute ethyl alcohol per g. lecithin. To each lecithin solution was then added 0.6 per cent. ash-free cholesterol. It should be mentioned that the concentrated lecithin solutions were of a yellowish colour, although in high dilution this colour is not noted.

The following Tables were taken from the antigen standardization records of this laboratory. Table II gives the titration picture of antigen Lot 462 , without the addition of lecithin solution (Titration 1), and after the addition of lecithin solution in the amounts of 0.3 per cent. (Titration 2), 0.5 per cent. (Titration 3), and 0.6 per cent. (Titration 4), to test-samples of the antigen.

It is evident from the Table that, without the addition of lecithin, the antigen gives no titre. The

TABLE I

DEGREE OF CLARITY OF ANTIGEN SUSPENSION IN SALT SOLUTION AND DISPERSIBILITY OF AGGREGATES (TITRATION EFFECT OF ADDITION OF CARDIOLIPIN TO KAHN ANTIGEN FOLLOWED BY LECITHIN, LEADING TO NON-DISPERSIBLE AGGREGATES IN ANTIGEN SUSPENSION, FOLLOWED BY THEIR DISPERSION)

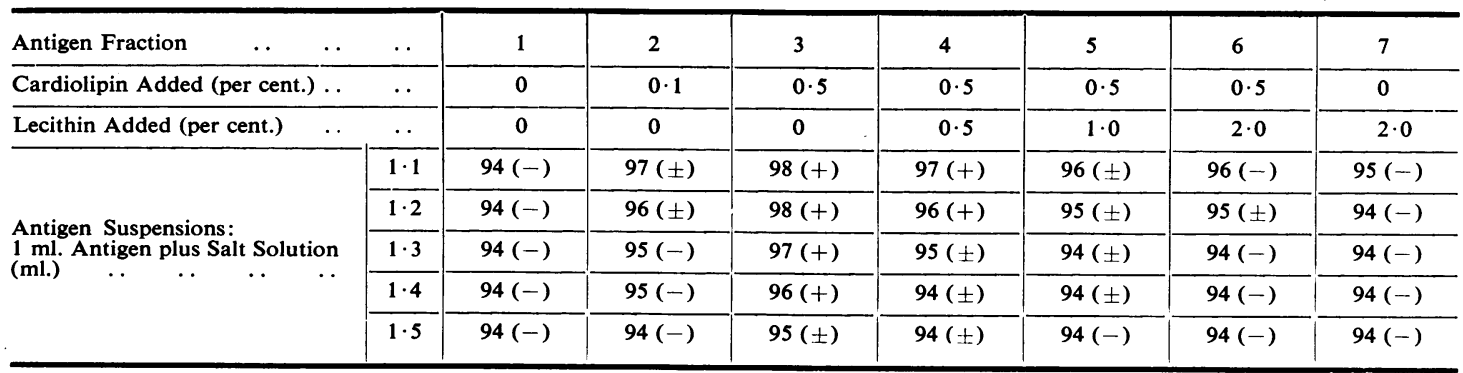

Figures in this Table and in Tables II, IV, VI indicate degree of clarity of suspension in salt solution:

$$
\begin{array}{ll}
94=\text { water-clear. } & 99=\text { trace clear. } \\
95=\text { very nearly water-clear. } & 100=\text { desirable opalescence, titre. } \\
96=\text { nearly water-clear. } & 101=\text { opalescent. } \\
97=\text { too clear. } & 102=\text { cloudy. } \\
98=\text { slightly too clear } & 103=\text { heavily turbid }
\end{array}
$$

98 Signs in brackets indicate degree of dispersion of aggregates in salt solution:
: heavily turbid.

$$
(-)=\text { aggregates dispersed. } \quad( \pm)=\text { aggregates partially dispersed. } \quad(+)=\text { aggregates not dispersed. }
$$


TABLE II

EFFECT OF ADDING CONCENTRATED LECITHIN TO KAHN ANTIGEN SHOWN BY RESULTS OBTAINED IN FOUR TITRATIONS, ILLUSTRATED WITH ANTIGEN SUSPENSIONS (ANTIGEN LOT 462) OF INCREASED AMOUNTS OF SALT SOLUTION

\begin{tabular}{|c|c|c|c|c|c|}
\hline \multicolumn{2}{|c|}{$\begin{array}{l}\text { Amount of Concen- } \\
\text { trated Lecithin Added } \\
\text { to Antigen (per cent.) }\end{array}$} & None & $0 \cdot 3$ & 0.5 & 0.6 \\
\hline Titration & .. & 1 & 2 & 3 & 4 \\
\hline \multirow{6}{*}{$\begin{array}{l}\text { Antigen Suspen- } \\
\text { sions: } 11 \mathrm{ml} \\
\text { Antigen plus } \\
\text { Salt Solution } \\
\text { (ml.) } \\
\text {.. } \quad . .\end{array}$} & $1 \cdot 1$ & $103(+)$ & $103(+)$ & $101(\div)$ & $101(-)$ \\
\hline & $1 \cdot 2$ & $103(+)$ & $103(t)$ & $100(-)^{*}$ & $100(-)^{*}$ \\
\hline & $1 \cdot 3$ & $103(+)$ & $103(\div)$ & $99(-)$ & $99(-)$ \\
\hline & $1 \cdot 4$ & $103(+)$ & $102(t)$ & $98(-)$ & $98(-)$ \\
\hline & $1 \cdot 5$ & $103(+)$ & $102( \pm)$ & $98(-)$ & $97(-)$ \\
\hline & $1 \cdot 7$ & $102( \pm)$ & $102( \pm)$ & $98(-)$ & $96(-)$ \\
\hline
\end{tabular}

For explanation of numbers $95-103$ and symbols, see footnote to Table I.

${ }^{*}$ Titre is $1 \mathrm{ml}$. antigen $+1 \cdot 2 \mathrm{ml}$. salt solution.

antigen suspensions in the entire titration range (consisting of $1 \mathrm{ml}$. antigen $+1 \cdot 1 \mathrm{ml}$. salt solution; $1 \mathrm{ml} .+1 \cdot 2 ; 1 \mathrm{ml} .+1 \cdot 3 ; 1 \mathrm{ml} .+1 \cdot 4 ; 1 \mathrm{ml}$. + $1 \cdot 5$; and $1 \mathrm{ml}$. $+1 \cdot 7)$ contain lipid aggregates that are non-dispersible in salt solution. This means that the aggregates will also not be dispersible in serum. The antigen therefore is not fit for trial use with serum, since the aggregates will be suspended in all sera with which the suspensions are mixed.

When 0.3 per cent. lecithin was added to a testsample of the antigen, partial dispersibility of the aggregates began to be noted, as indicated under Titration 2 in the Table. The antigen was still not fit for trial use, but 0.5 per cent. lecithin added to the antigen led to a typical titration picture. The titre was $1 \mathrm{ml}$. antigen $+1 \cdot 2 \mathrm{ml}$. salt solution. At this titre, the lipid aggregates in the resulting suspension were completely dispersed, and the opalescence conformed to the requirements of standard Kahn antigen. The same titre was obtained on the addition of 0.6 per cent. lecithin to the extract, but it did not seem desirable to use that amount when 0.5 per cent. was sufficient to provide a titre.

An interesting aspect of the addition of lecithin to antigen is that a "flat" titration picture is changed to a "sloping" titration. This change is illustrated in the Figure. The antigen extract without the addition of lecithin, or with the addition of 0.3 per cent. lecithin, gives essentially a "flat" titration picture, in that each of the seven lipid suspensions in the titration are within one zone, in this instance, in the zone of turbidity.

However, when either 0.5 or 0.6 per cent. lecithin is added to the extract, a "sloping" titration picture is obtained, the curve extending from the zone of turbidity, through the zone of desirable opalescence,

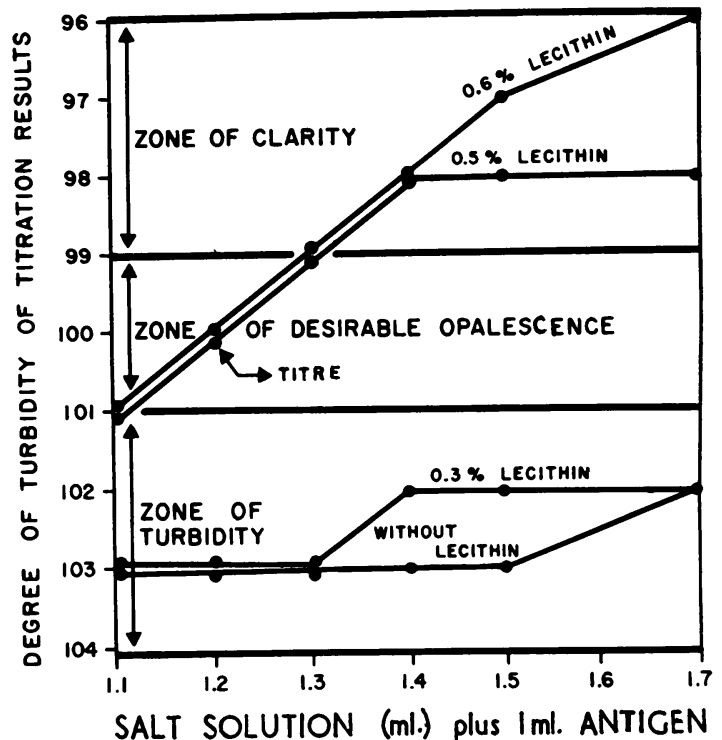

Figure-Change from a "flat" (undesirable) to a "sloping" (desırable) titration of Kahn antigen by addition of concentrated lecithin, in adjustment of Antigen Lot 462 .

into the zone of clarity. Experience with Kahn antigens extending through more than 30 years indicates that antigens giving "sloping" titrations retain their keeping qualities better than those giving "flat" titrations.

Having established a titre for Lot 462 , the next step was to determine the sensitivity of the antigen with syphilitic serum, using Kahn standard antigen as a control. Table III gives the comparative results

TABLE III

ADJUSTMENT OF KAHN ANTIGEN SENSITIVITY WITH CONCENTRATED LECITHIN TO BRING AN ANTIGEN TO STANDARD REQUIREMENTS

\begin{tabular}{|c|c|c|c|c|c|}
\hline \multirow[b]{2}{*}{$\begin{array}{c}\text { Serum } \\
\text { No. }\end{array}$} & \multicolumn{2}{|c|}{$\begin{array}{c}\text { Sensitivity of Lot } 462 \\
\text { same as } \\
\text { Standard Antigen }\end{array}$} & \multirow[b]{2}{*}{$\begin{array}{c}\text { Serum } \\
\text { No. }\end{array}$} & \multicolumn{2}{|c|}{$\begin{array}{c}\text { Sensitivity of Lot } 462 \\
\text { lower than } \\
\text { Standard Antigen }\end{array}$} \\
\hline & $\begin{array}{c}\text { Antigen } \\
\text { Lot } 462 \text {, } \\
0 \cdot 5 \text { per } \\
\text { cent. } \\
\text { Lecithin } \\
\text { Added } \\
\text { Titre } \\
1+1 \cdot 2\end{array}$ & $\begin{array}{l}\text { Kahn } \\
\text { Standard } \\
\text { Antigen } \\
\text { Lot } 203\end{array}$ & & $\begin{array}{c}\text { Antigen } \\
\text { Lot } 462 \text {, } \\
0.6 \text { per } \\
\text { cent. } \\
\text { Lecithin } \\
\text { Added } \\
\text { Titre } \\
1+1 \cdot 2\end{array}$ & $\begin{array}{l}\text { Kahn } \\
\text { Standard } \\
\text { Antigen } \\
\text { Lot } 203\end{array}$ \\
\hline $\begin{array}{r}1 \\
2 \\
3 \\
4 \\
5 \\
6 \\
7 \\
8 \\
9 \\
10\end{array}$ & $\begin{array}{lll} & - & \bar{C}^{*} \\
- & 4 & 4 \\
- & 3 & 4 \\
- & 2 & 4 \\
- & 1 & 4 \\
- & 1 & 4 \\
- & \pm & 2 \\
- & - & =\end{array}$ & $\begin{array}{rrr}-3 & 4 & 4 \\
\div & 4 & 4 \\
- & 4 & 4 \\
- & 2 & 4 \\
- & 1 & 4 \\
-\quad 1 & 4 \\
- & 3 \\
- & 1 \\
- & - & -\end{array}$ & $\begin{array}{l}11 \\
12 \\
13 \\
14 \\
15 \\
16 \\
17 \\
18 \\
19 \\
20\end{array}$ & $\begin{array}{ccc}- & - & -^{*} \\
- & 4 & 4 \\
- & 4 & 4 \\
- & \vdots & t \\
- & \vdots & 1 \\
- & \pm & 1 \\
- & - & 2 \\
- & - & -\end{array}$ & 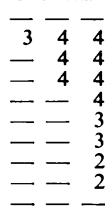 \\
\hline
\end{tabular}

* Opalescence conforms to that of standard antigen. 
obtained with eight weakly-positive syphilitic sera and two non-syphilitic sera.

It is evident that the antigen extract to which was added 0.5 per cent. lecithin gave results almost identical to those given by standard Kahn antigen, while the extract to which was added 0.6 per cent. lecithin gave results weaker than those given by standard antigen. Additional comparative studies with fifty syphilitic and non-syphilitic sera are not listed in these Tables because the results are of the same character as those given in Table III. Emphasis should be given to the fact that the tests with nonsyphilitic sera showed a degree of opalescence that conformed to standard requirements when employing the antigen corrected with 0.5 per cent. concentrated lecithin solution.

Occasionally, in titrating a newly-prepared antigen with salt solution, a "titration zone" will be noted. Such a zone is illustrated under Titration 1 in Table IV. In that titration, a suspension prepared by mixing $1 \mathrm{ml}$. antigen with $1.4 \mathrm{ml}$. salt solution, contains dispersible lipid aggregates, and on the surface it might seem suitable as a titre for trial use with serum. However, when $1 \mathrm{ml}$. antigen is mixed either with $0.1 \mathrm{ml}$. more or $0.1 \mathrm{ml}$. less of salt solution (actually, with 1.3 or $1.5 \mathrm{ml}$. salt solution) the resulting suspensions contain non-dispersible aggregates and are not suitable for trial use. Therefore, the use of $1.4 \mathrm{ml}$. salt solution would result in a suspension having too narrow a zone for a titre.

TABLE IV

EFFECT OF ADDING CONCENTRATED LECITHIN TO KAHN ANTIGEN SHOWN BY RESULTS OBTAINED IN THREE TITRATIONS, ILLUSTRATED WITH ANTIGEN SUSPENSIONS (ANTIGEN LOT 190) OF INCREASED AMOUNTS OF SALT SOLUTION, AND SHOWING THAT THE ADDITION OF
LECITHIN MAY OVERCOME A "TITRATION ZONE"

\begin{tabular}{|c|c|c|c|c|}
\hline \multicolumn{2}{|c|}{$\begin{array}{c}\text { Amount of Concentrated } \\
\text { Lecithin Added to } \\
\text { Antigen (per cent.) }\end{array}$} & \multirow{2}{*}{ None } & \multirow{2}{*}{$\frac{0 \cdot 3}{2}$} & \multirow{2}{*}{ 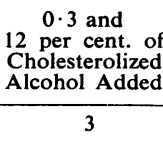 } \\
\hline Titration & .. & & & \\
\hline \multirow{6}{*}{$\begin{array}{l}\text { Antigen Suspen- } \\
\text { sions: } \\
1 \mathrm{ml} \text {. Antigen } \\
\text { plus Salt } \\
\text { Solution (ml.) .. }\end{array}$} & $1 \cdot 1$ & $103(+)$ & $100( \pm)$ & $101( \pm)$ \\
\hline & $1 \cdot 2$ & $103(+)$ & $99 \frac{1}{2}(-)^{*}$ & $100 \frac{1}{2}(-)$ \\
\hline & $1 \cdot 3$ & $103( \pm)$ & $98(-)$ & $100(-)$ \\
\hline & $1 \cdot 4$ & $103(-)$ & $97(-)$ & $99 \frac{1}{2}(-)$ \\
\hline & 1.5 & $102( \pm)$ & $96(-)$ & $99(-)$ \\
\hline & $1 \cdot 7$ & $103(+)$ & $95(-)$ & $98 \frac{1}{2}(-)$ \\
\hline
\end{tabular}

For explanation of numbers ranging from 95 to 103 and symbols, see footnote to Table I.

Titre is $1 \mathrm{ml}$. antigen $+1.15 \mathrm{ml}$. salt solution.

On the addition of $0 \cdot 3$ per cent. of lecithin to such an antigen, a "sloping" titration picture is obtained, with a titre of $1 \mathrm{ml}$. antigen $+1.15 \mathrm{ml}$. salt solution. Yet, the obtaining of a titre did not prove to be the answer to this antigen standardization problem as was shown by the fact that, when tested with syphilitic sera, the antigen proved to be undersensitive compared with standard Kahn antigen (Table V).

TABLE V

ADJUSTMENT OF KAHN ANTIGEN SENSITIVITY WITH CONCENTRATED LECITHIN TO BRING AN ANTIGEN TO
STANDARD REQUIREMENTS

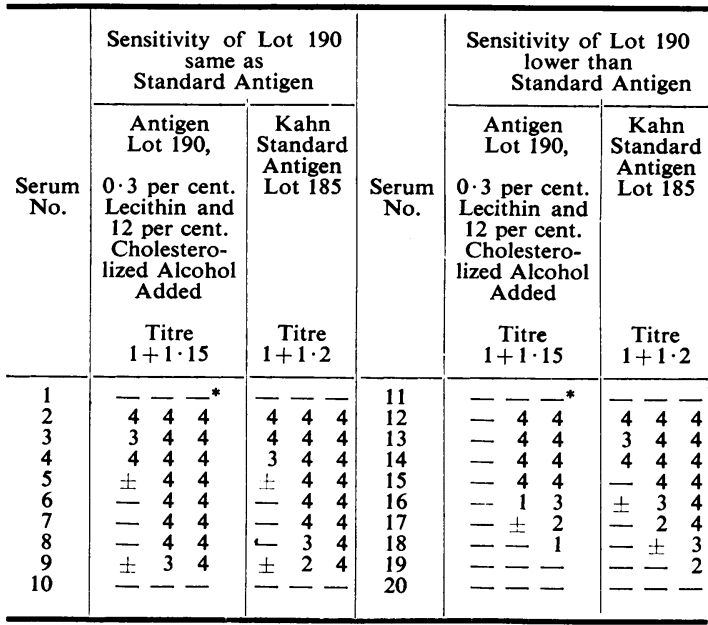

* Opalescence conforms to that of standard antigen.

It may be that 0.3 per cent. lecithin proved to be a greater amount than was necessary to add to the antigen for correct sensitivity, but because of the correctly sloping titration, it did not seem desirable to change this amount of lecithin. Accordingly, another step was used to increase the sensitivity of the antigen, viz., dilution of the antigen with ethyl alcohol containing 0.6 per cent. cholesterol, to conform to the amount of this lipid contained in the antigen. That step consisted of diluting two test samples of the antigen, 6 and 12 per cent. respectively, with cholesterolized alcohol. It was found that the 12 per cent. diluted sample brought the sensitivity of the antigen to standard requirements. Evidently this dilution did not overcome the lecithin effect on the antigen.

Tables VI and VII give yet another illustration of an antigen, originally not fit for use because it gave no titre, which was converted into standard Kahn antigen by the addition of the optimum amount of concentrated lecithin (in this case 0.5 per cent.).

\section{Correction of Antigens that almost meet Standard Requirements}

A newly-prepared lipid extract may, to a small degree, prove to be either more or less sensitive than standard Kahn antigen. Such an extract can often 
TABLE VI

EFFECT OF ADDING CONCENTRATED LECITHIN TO KAHN ANTIGEN SHOWN BY RESULTS OBTAINED IN FIVE TITRATIONS, ILLUSTRATED WITH ANTIGEN SUSPENSIONS (ANTIGEN LOT 466) OF INCREASED AMOUNTS OF SALT SOLUTION

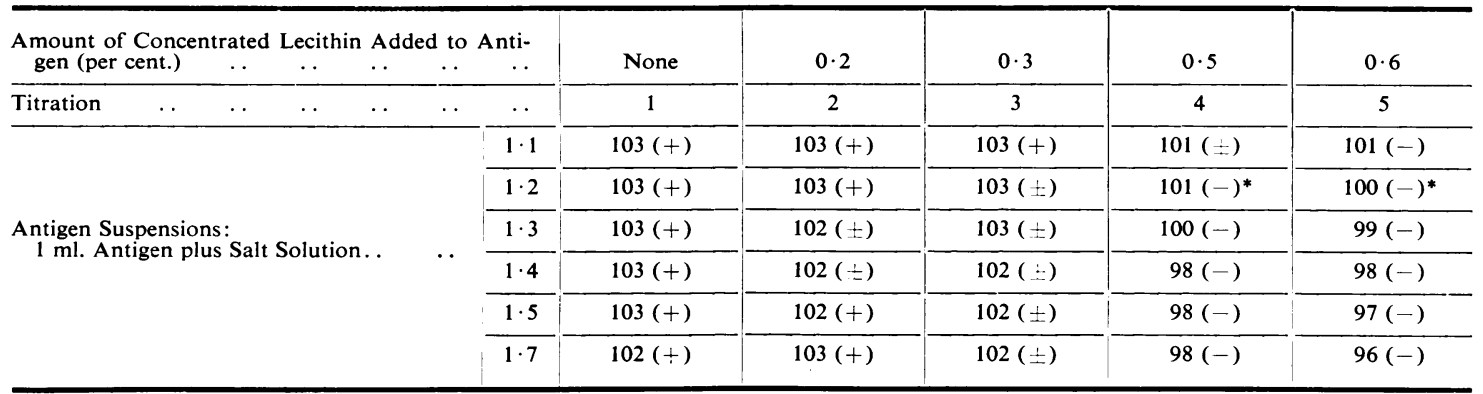

For explanation of numbers ranging from 96 to 103 and symbols, see footnote Table I.

* Titre is $1 \mathrm{ml}$. antigen $+1 \cdot 2 \mathrm{ml}$. salt solution.

TABLE VII

ADJUSTMENT OF KAHN ANTIGEN SENSITIVITY WITH CONCENTRATED LECITHIN TO BRING AN ANTIGEN TO STANDARD REQUIREMENTS

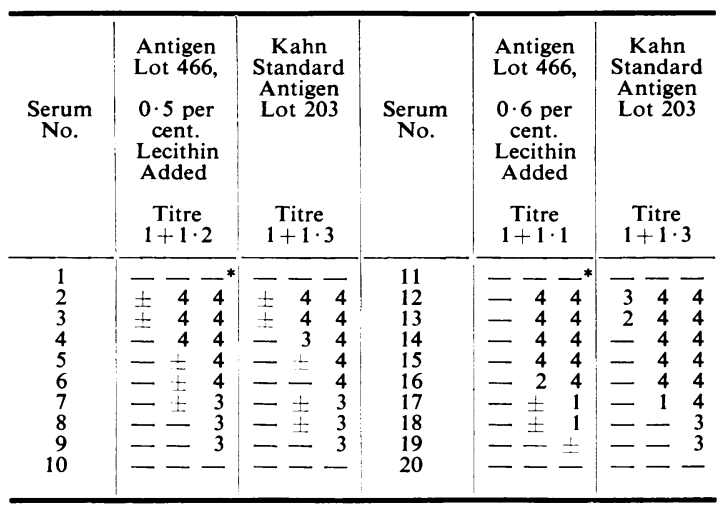

* Opalescence conforms to that of standard antigen.

be brought to the sensitivity of standard antigen by changing the titre. Thus, suppose that at the titre of $1+1 \cdot 3$ the antigen is slightly more sensitive than Kahn standard antigen, then, by a change in titre to $1+1 \cdot 4$ or perhaps $1+1 \cdot 5$, the antigen sensitivity may be reduced to standard requirements. Alternatively, suppose that at a titre of $1+1 \cdot 3$ the antigen is slightly less sensitive than the standard, then by a change in titre to $1+1 \cdot 2$ or perhaps $1+1 \cdot 1$, the antigen sensitivity may be increased to standard requirements. It is assumed that these changes in titre do not affect the correct opalescent appearance of the negative reactions.

If a change in the titre of the antigen does not produce the desired results, dilution of the antigen with cholesterolized alcohol is undertaken. Of interest is the fact that a 10 or 20 per cent. dilution may increase the sensitivity of an under-sensitive antigen, or decrease the sensitivity of an oversensitive antigen, to standard requirements.

This unusual effect of dilution may stem from the reason for the too low or too high sensitivity of the antigen. Thus, if an antigen is under-sensitive primarily because of a relative excess of lecithin in relation to cardiolipin, the reduction of the lecithin by dilution should increase the sensitivity of the antigen. It is true that such dilution also reduces the amount of cardiolipin, which in turn would tend to lower the sensitivity, but apparently the dominant effect of dilution on this type of antigen is the increase in sensitivity resulting from the reduction in the amount of lecithin. However, if the antigen is low in sensitivity primarily because of an insufficient amount of cardiolipin, then any dilution of the antigen with cholesterolized alcohol would only further reduce the sensitivity by reducing the amount of this lipid.

Let us now consider an antigen too high in sensitivity, in which dilution with cholesterolized alcohol reduces the sensitivity. Most likely such an antigen is too rich in cardiolipin, and dilution reduces the amount of this lipid. It is recognized that dilution also tends to reduce the amount of lecithin in the antigen, which should lead to an increase in sensitivity. If, however, the dominant factor in the high sensitivity of the antigen is the high concentration of cardiolipin, the effect of diluting this lipid may be far greater than the effect of diluting the lecithin.

Years ago, in this laboratory, over-sensitive antigens were reduced in sensitivity by increasing the concentration of the lipids of the noncholesterolized extracts. The technique was to evaporate a given fraction of an extract and dissolve the residue in the cholesterolized extract. In such an instance, the reduction in the sensitivity may have 
been largely due to the increase in the amount of lecithin in the antigen obtained from the evaporated residue. This increased amount of lecithin in the antigen must have masked the accompanying increase in the amount of cardiolipin contained in the evaporated residue.

Another aspect of antigen preparation may be mentioned. Powdered heart muscle that produces Kahn antigen of under-sensitivity may be modified by a simple technique to produce an antigen close to standard requirements. All that is necessary is to extract the powder with ether, according to the usual technique, and then to expose it to air by spreading it out in a thin layer at room temperature. Such exposure may be for from 24 to 72 hours, as determined by trial, after which the extraction with alcohol is carried out. It is possible that this exposure breaks down some of the lecithin or its precursors without affecting the more stable cardiolipin, thus leading to the increase in sensitivity of the extract. Occasionally also, powdered heart muscle, which produces an under-sensitive antigen, has to be aged for a month or more so that it may yield an extract close in sensitivity to standard requirements. It may be that here also we are dealing with a situation in which some lecithin is broken down because of the aging of the powder.

\section{Summary}

Certain lipid extracts, prepared according to the Kahn antigen technique, when mixed with salt solution, result in antigen suspensions containing heavy non-dispersible lipid aggregates throughout the antigen titration range. Such extracts, which it had not been possible to correct to Kahn standard antigen because of the persistence of these aggregates, were found to be readily corrected by the addition of a small amount of a concentrated solution of lecithin. The lecithin so modified the extract as to produce, with salt solution, antigen suspensions with the following characteristics:

(1) They contain dispersible aggregates.

(2) They permit a correct antigen titre to be obtained.

(3) They give positive flocculation results of standard sensitivity.

(4) They give negative flocculation results of correct opalescence.

It is believed that the non-dispersible lipid aggregates in antigen suspensions are due to the presence of an excess of cardiolipin or a cardiolipin-like substance in relation to lecithin in the lipid extract. When a known solution of cardiolipin was added to Kahn antigen, dispersible aggregates in the antigen suspensions were changed to non-dispersible aggregates, and these, in turn, were rendered dispersible by the addition to the antigen of a small amount of a concentrated solution of lecithin.

\section{REFERENCES}

Kahn, R. L. (1950). "Serology With Lipid Antigen-With Special Reference to Kahn and Universal Reactions". Williams and Wilkins, Baltimore.

(1951). "An Introduction to Universal Serologic Reaction in Health and Disease". Commonwealth Fund, New York; Harvard University Press, Cambridge, Mass.; Oxford University Press, London.

Pangborn, M. C. (1945). J. biol. Chem., 161, 71.

Pangborn, M. C. (1945). J.

Wheeler, A. H., Brandon, E. M., and Kahn, R. L. (1947). Amer. J. clin. Path., 17, 117. 